\title{
A Systematic Review of Learning through Mobile Augmented Reality
}

\author{
https://doi.org/10.3991/ijim.v12i3.8404
}

\author{
Hillevi Hedberg, Jalal Nouri $\left.{ }^{\varpi}\right)$, Preben Hansen, Rahim Rahmani \\ Stockholm University, Stockholm, Sweden \\ jalaledsv.su.se
}

\begin{abstract}
In the beginning of this millennium, researchers started to see the potential of using Augmented Reality (AR) in educational settings and foresaw that further research within the field is needed. Since then, AR research have taken many different approaches. This is also true for AR in relation to pedagogical purposes. In recent years, learning through mobile augmented reality has become increasingly interesting due to the mobile devices small form factors and their ability to let the students move around freely while learning. This study investigates mobile supported augmented reality for learning. It attempts to make a systematic review of how learning and pedagogical aspects have been approached in the articles. Based on a review of previous literature of mobile AR systems for pedagogical purposes, published between 2000-2017, we present findings demonstrating the mobile platforms used in AR studies, the educational levels focused, pedagogical approaches employed, and educational subjects focused. Based on these findings, trends are identified and future work discussed.
\end{abstract}

Keywords-mobile augmented reality, mobile learning, systematic review, augmented reality, mobile devices

\section{Introduction}

It was in the beginning of this millennium that researchers started to really see the potential of using AR in education and foresaw further research within the field [1] [2]. Since then, many variations and approaches have been taken in the design of AR used for pedagogical purposes and there's a need for an overview of what has been studied within the field [3]

Augmented Reality (AR) is a field in which virtual objects are integrated into a real environment in real time. As explained by [4], AR supplements the real world with virtual, computer-generated, objects that appear to coexist in the same space as the real world. In other words, AR is a way to enhance the real world and it may be achieved by adding a layer of virtual-objects on top of the real world.

AR emerged as an own research field as late as in the 1990s due to its high technological demands [4]. [5] did an early survey of the research field and decided to define 
AR with following three characteristics: 1) Combines real and virtual, 2) Interactive in real time and 3) Registered in 3-D.

AR technologies can be helpful when a person is unable to detect something with his or her own senses. AR can be used to let a computational device process information which else would have taken longer time or even be impossible for a human. This includes calculations, comparisons and sorting of non-subjective objects which are tasks that computational devices are good at carrying out. Furthermore, AR could be used to blur out objects that are irrelevant.

The use of mobile AR systems has opened up for new possibilities within the research field. As explained by [6], the smaller size on the devices solves previous problems with AR systems concerning its usability and scalability. These smaller mobile devices on which the AR system can be loaded have made the AR systems more user friendly and become even more available in everyday life. As [6] and [7] write that there is "a broad consumer interest in very small form factor devices and displays such as cell phones and handheld computers" which has dramatically accelerated the development in the mobile AR field.

While we can easily imagine applications for AR in many fields, we are interested in what possibilities AR applications may generate for educational settings [8]. Many authors [3][9][10] have identified learning as an interesting and promising field in which AR could be applied. [3] writes that AR systems could "help learners develop skills and knowledge that can be learned in other technology environments but in a more effective way" and as [9] writes "AR can enhance our situated learning by augmenting our realties more effectively". According to several, such as [10] [11] [12], AR increases the effectiveness of and motivation for learning. [13] writes that AR can effectively improve achievements of learners in various subjects such as geography, history, mathematics, biomedicine, arts and humanities. The study by [13] found that AR technology played an effective role in improving the learning of non-high-scoring students.

A review of previous studies of mobile AR systems for pedagogical purposes would make it possible to see in which direction mobile AR systems for education are heading and how future mobile AR systems should be designed to best fit the needs of future students so they can more effectively improve their learning. This review would be a pointer for future studies and researchers to see what has previously been done within the field.

The goal of this study is to make a systematic review of pedagogical uses of mobile AR. To achieve the goal, the following four research questions were defined:

RQ1: Which mobile platforms are used in AR studies?

RQ2: Which educational level are the AR systems aimed for?

RQ3: Which pedagogical methods are used?

RQ4: For which subjects are the systems used? 


\section{Methodology}

\subsection{Data collection}

In this section, the systematic literature review protocol which was deployed for this research project is presented. The protocol has been used ensure the consistency of the literature review [14] and it includes specific steps to be followed in the review being conducted. Following pre-defined steps will allow the results to be reproduced by other researchers carrying out the same literature review.

\subsection{Selection of article databases}

To make the number of articles manageable the articles was retrieved from a set of selected article databases. The selected databases for this project was IEEE Xplore Digital Library, Elsevier, and ACM Digital Library.

\subsection{Search terms}

The set of search keywords presented in the list below were defined to find relevant articles to answer the research question. The search was carried out between April and May 2017. To narrow the search Boolean search strings were used to make the search keywords.

- Augmented Reality AND;

- Mobile OR Tablet OR Smartphone AND;

- Education OR Learning OR Pedagogy

\subsection{Selection of papers: Inclusion and exclusion criteria}

Once the articles were found through the search they were further evaluated. Articles were only included in the literature review if they met a set of pre-defined criteria (see Table 1, below). These criteria were aimed to sort out articles that were not related to the research goal. Articles that didn't meet the criteria were not further examined whereas articles that passed the screening were retrieved in full-text and reviewed in the analysis phase.

\subsection{Data analysis}

Content analysis was selected as the analysis method for this study. The motivation is that the aim of the study is to find new themes within the research field through examining the existing research on mobile AR systems for educational purposes. Furthermore, it is assumed that most of the articles will not deal with statistical data that can easily be compared. Articles that have been selected through the selection process were decoded and categorized into the following categories: Educational level, Research design, Mobile platforms, Location, Subject, Learning outcomes, and Pedagogical method. 
Paper-A Systematic Review of Learning through Mobile Augmented Reality

Table 1. Inclusion criteria for the systematic review of AR use in pedagogical settings

\begin{tabular}{|l|l|}
\hline \multicolumn{1}{|c|}{ Inclusion criteria } & \multicolumn{1}{c|}{ Motivation } \\
\hline Published between 2000-2017 & $\begin{array}{l}\text { Papers regarding augmented reality for educational purposes started to be } \\
\text { published year 2000 and forward. }\end{array}$ \\
\hline Focused on Augmented Reality & It is a requirement that the study is focused on AR. \\
\hline Research on mobile systems & It is requirement that the study is focused on mobile applications. \\
\hline $\begin{array}{l}\text { Research on education or } \\
\text { pedagogical method at any } \\
\text { educational level }\end{array}$ & $\begin{array}{l}\text { It is a requirement that the study focus on pedagogical applications of } \\
\text { mobile augmented reality }\end{array}$ \\
\hline Written in English & It is a requirement that the study is written in English. \\
\hline $\begin{array}{l}\text { Peer-reviewed conference and } \\
\text { journal articles }\end{array}$ & It is a requirement that the article has been peer-reviewed. \\
\hline
\end{tabular}

\section{$3 \quad$ Results}

This chapter presents the results from the literature review. Table 2 shows the number of research papers retrieved from respective article database. In total 604 research papers were found through the pre-defined search keywords.

After application of inclusion and exclusion criteria a total of 73 articles was selected.

Table 2. Search results for the systematic review of AR use in pedagogical domain

\begin{tabular}{|c|l|c|}
\hline $\begin{array}{c}\text { Data- } \\
\text { base }\end{array}$ & \multicolumn{1}{|c|}{ Search string } & Nr of research papers \\
\hline IEEE & $\begin{array}{l}\text { ((Augmented Reality) AND (Mobile OR Tablet OR } \\
\text { Smartphone) AND (Education OR Learning OR Pedagogy)) }\end{array}$ & 316 \\
\hline ACM & $\begin{array}{l}\text { (+augmented +reality) AND (mobile tablet smartphone) AND } \\
\text { (education pedagogy learning) }\end{array}$ & 203 \\
\hline Elsevier & $\begin{array}{l}\text { (Augmented Reality) AND (Mobile OR Tablet OR } \\
\text { Smartphone) AND (Education OR Learning OR Pedagogy) } \\
\text { AND LIMIT-TO(topics, "augment reality") }\end{array}$ & 85 \\
\hline
\end{tabular}

\subsection{Educational level}

The first category, the educational level, was related to the research question "Which educational level are the AR systems aimed for?". In the educational level category, the research papers could be divided into six sub-categories. These categories are shown in figure 1 . Three of the research papers belonged to two or more subcategories. For example, two studies dealt with both elementary school and junior high school students and a third study dealt with students ranging from elementary school, junior high school to high school. This means that there are 77 entries in Figure 1. instead of 73 . From the figure it is shown that the majority $(46,58 \%)$ of the research papers involved education at university level. Second most studied educational level were elementary school $(24,66 \%)$ which were followed by Junior High School (15,07\%), High School (8,22\%) and Pre-school (8,22\%). Last were two papers that did not state any specific educational level $(2,74 \%)$. 


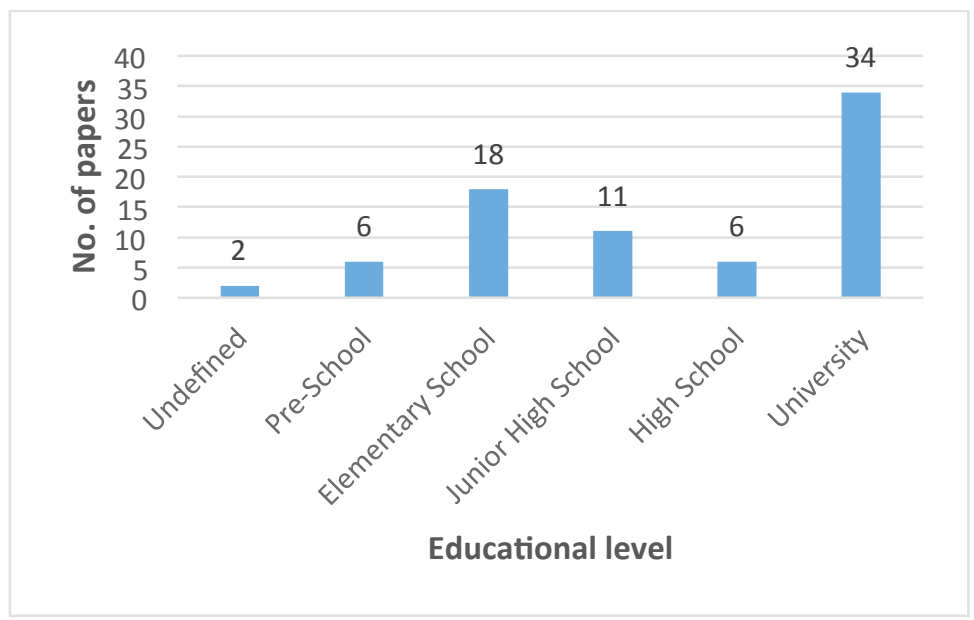

Fig. 1. Educational level

\subsection{Research designs}

The second category was the Research design. This category aimed to find out which research strategies that were used to carry out the research projects. A total of five sub-categories were identified, see Figure 2. The most common were the Design Research approach (49,32\%). In Design Research, the researchers identified a problem which they tried to solve through the design, development and evaluation of an artefact. Another common approach was the Experiment approach (28,77\%). The Experiment approach commonly involved a set of students which were asked to perform specific tasks that were normally not part of their education. The other three subcategories were Surveys (9,59\%), Mixed Methods (6,85\%) and Case Studies (5,48\%).

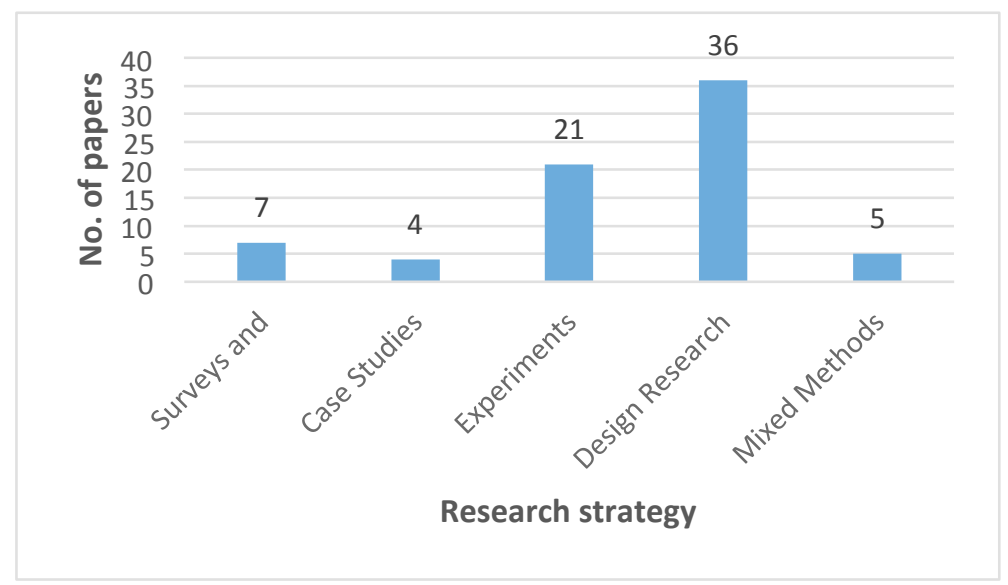

Fig. 2. Research strategy 


\subsection{Mobile platforms}

Figure 3. shows the most common platform used in the research papers. The aim of the mobile platform category is to answer the research question "Which mobile platforms are used?". There were fourteen papers which included multiple mobile platforms such as smartphones and tablets. Mobile phones and smart phones were the most studied mobile platforms $(43,84 \%)$ followed by tablets $(27,40 \%)$. There were twenty of the research papers $(27,40 \%)$ that did not specify which mobile platform they used in the project. Five papers were placed in the 'Other' sub-category which includes three studies that used their own platform, one study that used a digital pen and one study that used smart glasses.

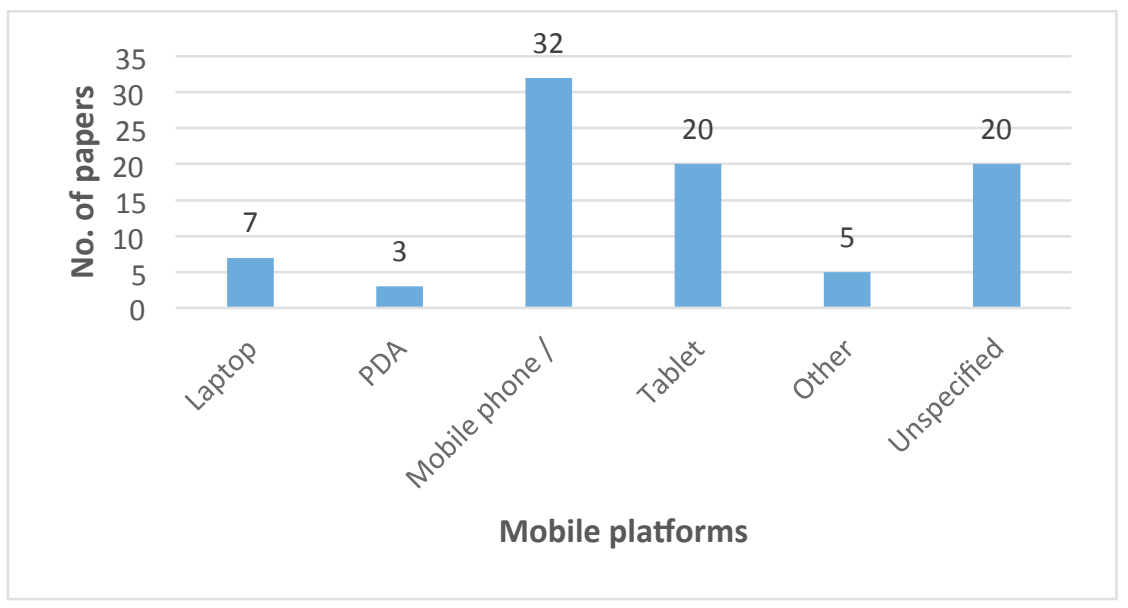

Fig. 3. Mobile platforms

\subsection{Location}

There were 27 papers that studied mobile AR for educational purposes in Asia $(36,99 \%)$ which were slightly more than the 21 studies that took place in Europe $(28,77 \%)$. These two locations were followed by North America (12,33\%), South America (10,96\%), Middle East (6,85\%) and Australia and the Oceania $(4,11 \%)$ as shown in Figure 4. 


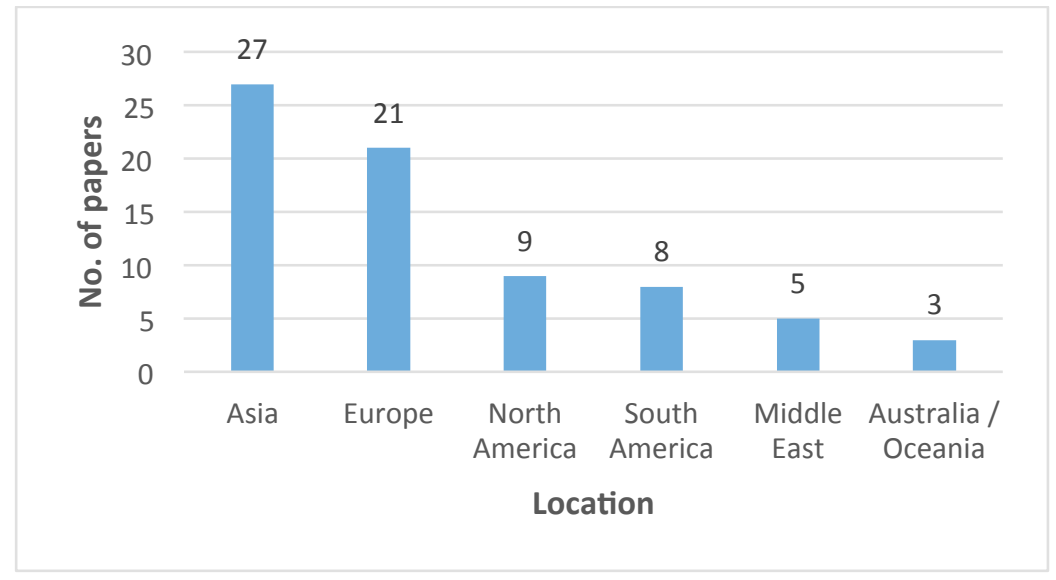

Fig. 4. Location

\subsection{Subjects}

Related to the research question "For which subjects are the systems used?", a clear majority of research papers dealt with Natural science (27,40\%), see figure 5. Here, natural science includes Physics, Chemistry and Biology. Natural science was followed by Language $(10,96 \%)$ and History $(10,96 \%)$.

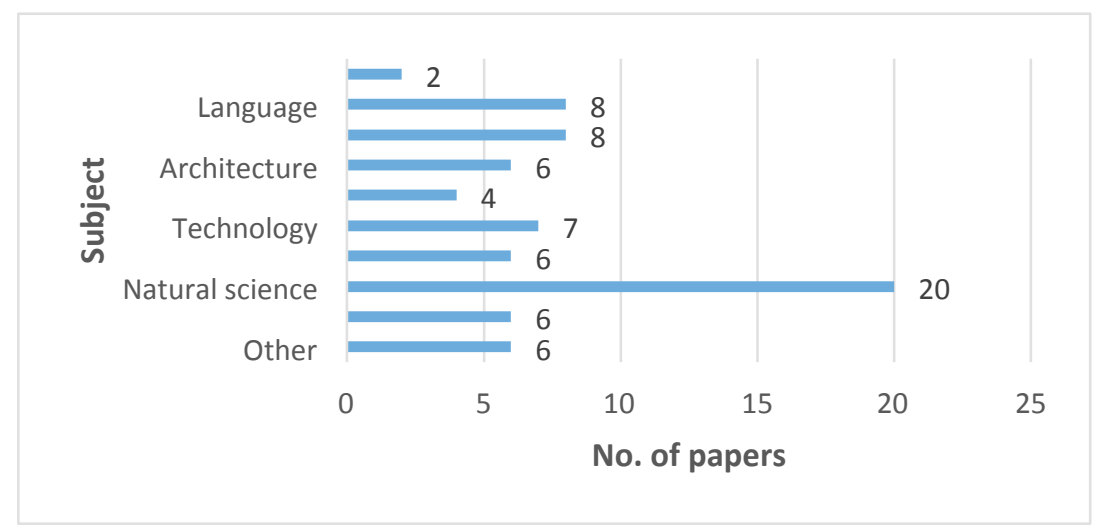

Fig. 5. Subjects

\subsection{Learning outcomes}

The learning outcomes from the research projects are relevant when reviewing the pedagogical use of mobile AR since it indicates how well mobile AR are received by actual users. Figure 6 . shows common learning outcomes identified in the 73 research papers. In overall, all studies except two found mobile AR to have had positive learning outcomes. From those 71 papers, 28 could confirm that they found that the AR 
technology improved the students study results $(34,15 \%)$. The majority of papers $(54,88 \%)$ concluded that the mobile AR technology improved the students' motivation and increased their engagement in learning. Other learning outcomes included improved collaboration skills $(2,44 \%)$, improvement of the students' creativity $(3,66 \%)$ and improvement of the students' problem-solving skills $(4,88 \%)$.

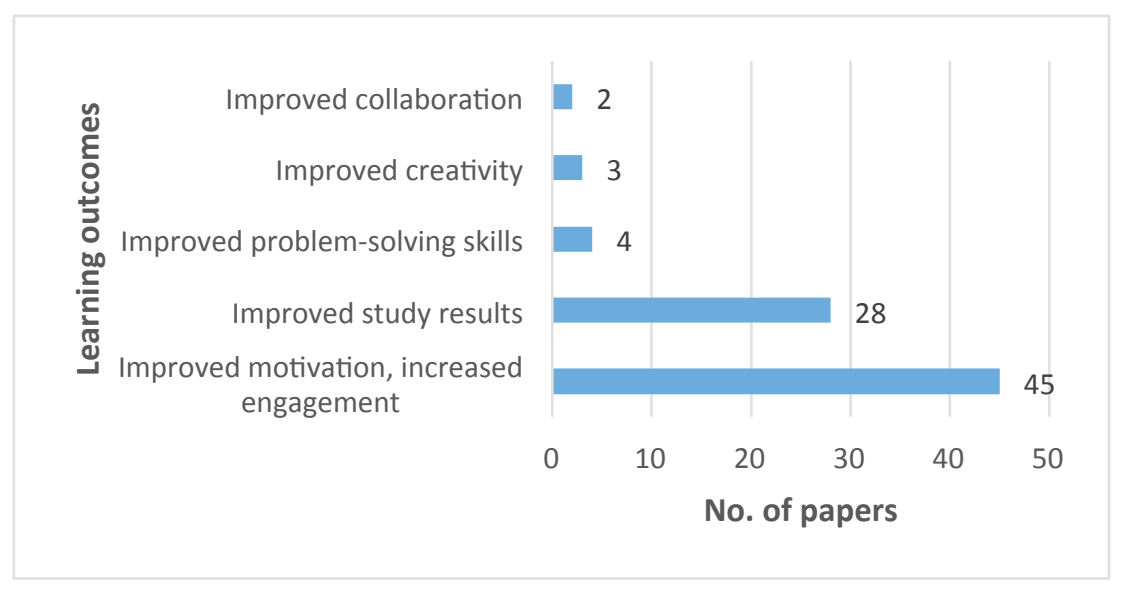

Fig. 6. Learning outcomes

\subsection{Pedagogical methods}

In terms of the research question "Which pedagogical methods are used?", many of the research papers were not explicitly describing the pedagogical method employed. Instead they based their research on different pedagogical methods and strategies. Figure 7. shows which learning strategies which were used in the 73 research papers. There were some papers that were classified into multiple learning strategies in Figure 13. The most common learning approach was interactive learning $(33,71 \%)$ followed by inquiry-based learning $(30,34 \%)$ and collaborative learning $(14,61 \%)$. 


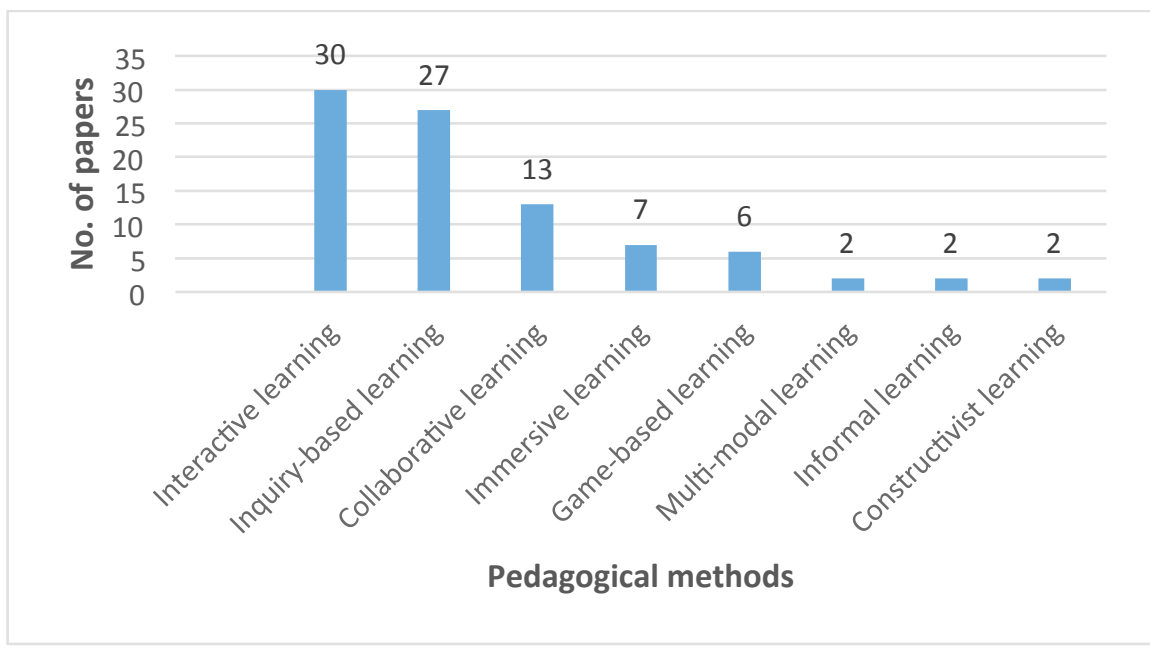

Fig. 7. Pedagogical method

\section{Discussion}

This systematic literature review aimed at providing an overview of relevant studies on mobile augmented reality learning with a particular focus on learning that take place in formal educational settings. The results indicate that the most common device used for pedagogical applications of mobile AR is smartphones. Furthermore, in the articles published at ACM, IEE and Elsevier the results shows that the most common subject the AR systems were implemented in was natural science while the most common educational level was university level. Several pedagogical approaches were employed in the selected studies, namely: interactive learning, inquiry-based learning, collaborative learning, immersive learning, game-based learning, multi-modal learning, informal learning and constructivist learning. From these learning strategies, the three most commonly stated approaches were interactive learning, inquiry-based learning and collaborative learning.

The literature review has also shown that most of the research on pedagogical use of mobile AR in formal settings has been carried out in Asia and Europe. In addition, the review identified design-based research as the most common research strategy. In other words, most of the research papers tried to solve a school-related problem through the development and evaluation of an artefact: a mobile AR system. Finally, the analysis showed that 71 of the 73 research papers found the use of pedagogical mobile AR in schools results in successful learning outcomes.

A limitation of the research is that only articles from three article databases are used. This means that there is a potential that results may vary if additional databases are included in the research. However, since the three selected databases are relatively large and contains most of the published work within the research field potential changes are deemed to be relatively small. 
Future research should look at pedagogical use of mobile AR in relation to more than just schools. For example, other researchers have identified mobile AR to have the possibility to promote informal learning in museums, entertainment parks and games. Other pedagogical uses of mobile AR which can be further explored is the use of AR in health education and at work.

\section{$5 \quad$ References}

[1] Shelton, B.E. (2002) Augmented Reality and Education Current Projects and the Potential for Classroom Learning. New Horizons for Learning Vol. 9 No. 1 December 2002.

[2] Billinghaust, M. (2002) Augmented Reality in Education. December 2002 New Horizons for Learning.

[3] Wu, H-K, Lee, S.W-Y, Chang, H-Y, Liang, J-C. (2012). Current status, opportunities and challenges of augmented reality in education. Journal of Computers \& Education 62 (2013) pp 41-49.

[4] Krevelen, D.W.F. van (2007) Augmented Reality: Technologies, Applications, and Limitations. Vrije Universiteit Amsterdam, Department of Computer Science, the Netherlands.

[5] Azuma, R.T. (1997) A Survey of Augmented Reality. Presence: Teleoperators and Virtual Environments 6, 4 (August 1997), pp. 355-385. https://doi.org/10.1162/pres.1997.6.4.355

[6] Wagner, D., Schmalstieg, D. (2003) First Steps Towards Handheld Augmented Reality. Proceedings of the 7th International Conference on Wearable Computers, IEEE Computer Society Press, 2003, ISBN: 0-7695-2034-0, pp 127 - 135. https://doi.org/10.1109/ISWC. 2003.1241402

[7] Schmalstieg, D., Langlotz, T., Billinghurst, M. (2011). Augmented Reality 2.0. In Virtual Realities, 2011 by Seminar, D. and editors Brunnett, G., Coquillart, S., Welch, G. ISBN 978-3-211-99177-0. Chapter 2, pp. 13-37. https://doi.org/10.1007/978-3-211-99178-7 2

[8] Yuen, S., Yaoyuneyong, G., Johnson, E. (2011). Augmented reality: An overview and five directions for AR in education. Journal of Educational Technology Development and Exchange, 4(1), pp 119-140. https://doi.org/10.18785/jetde.0401.10

[9] FitzGerald, E., Ferguson, R., Adams, A., Gaved, M., Mor, Y., Thomas, R. (2013). Augmented reality and mobile learning: the state of the art. International Journal of Mobile and Blended Learning, 5(4) pp. 43-58. https://doi.org/10.4018/ijmbl.2013100103

[10] Kaufmann, H. (2003). Collaborative Augmented Reality in Education. 'Imagina Conference 2003', issued by: Imagina;. Monaco Mediax, Monaco (invited).

[11] Kesim, M., Ozarslan, Y. (2012) Augmented reality in education: current technologies and the potential for education. Procedia - Social and Behavioral Sciences 47 (2012) pp. 297 302. https://doi.org/10.1016/j.sbspro.2012.06.654

[12] Chiang, T.-H.-C., Yang, S.-J.-H., \& Hwang, G.-J. (2014). An Augmented Reality-based Mobile Learning System to Improve Students' Learning Achievements and Motivations in Natural Science Inquiry Activities. Educational Technology \& Society, 17 (4), 352-365.

[13] Zhang, J., Liu, T-C, Sung, Y-T, Chang, K-E (2015). Using Augmented Reality to Promote Homogeneity in Learning Achievement. 2015 IEEE International Symposium on Mixed and Augmented Reality - Media, Art, Social Science, Humanities and Design. https://doi.org/10.1109/ISMAR-MASHD.2015.17

[14] Okoli, C., Schabram, K. (2010). A Guide to Conducting a Systematic Literature Review of Information Systems Research. Sprouts: Working Papers on Information Systems, 10(26). http://sprouts.aisnet.org/10-26. 


\section{Authors}

Hillevi Hedberg has a master in Computer and Systems sciences from the department of Computer and system sciences, Stockholm University.

Jalal Nouri is an associate professor at the department of Computer and system sciences, Stockholm University.

Preben Hansen is an associate professor at the department of Computer and system sciences, Stockholm University.

Rahim Rahmani is an associate professor at the department of Computer and system sciences, Stockholm University.

Article submitted 09 February 2018. Resubmitted 09 March 2018. Final acceptance 08 May 2018. Final version published as submitted by the authors. 